\title{
Medical Research Council Hot Topic workshop report: Planning a UK Nutrition and Healthy Life Expectancy Trial
}

\author{
Jennifer Carter ${ }^{1}$ @ | John Mathers ${ }^{2}$ | Susan Fairweather-Tait ${ }^{3}$ | Susan Jebb ${ }^{4}$ | \\ Naveed Sattar $^{5}$ | Amy Jennings ${ }^{3}$ | Anne-Marie Minihane ${ }^{3}$ (i)
}

${ }^{1}$ Clinical Trial Service Unit and Epidemiological Studies Unit (CTSU), Nuffield Department of Population Medicine, University of Oxford, Oxford, UK

${ }^{2}$ Human Nutrition Research Centre, Population Health Sciences Institute, Newcastle University, Newcastle upon Tyne, UK

${ }^{3}$ Norwich Medical School, University of East Anglia, Norwich, UK

${ }^{4}$ Department of Primary Care Health Sciences, University of Oxford, Oxford, UK

${ }^{5}$ Institute of Cardiovascular and Medical Sciences, University of Glasgow,

Glasgow, UK

\section{Correspondence}

Anne-Marie Minihane, Department of Nutrition and Preventive Medicine, Norwich Medical School, BCRE

University of East Anglia (UEA), Norwich, UK.

Email: a.minihane@uea.ac.uk

Funding information

Medical Research Council, Grant/Award

Number: MC_PC_19015

\begin{abstract}
There is a drive in the UK to harness findings from novel fundamental and efficacy nutritional research and, through inter-disciplinary and multi-agency collaborations, to improve eating behaviour for the benefit of population health. This report summarises the progress made during the Medical Research Councilfunded Hot Topic workshop on the planning for a potential UK-wide nutrition primary prevention randomised controlled trial with incident disease as the study endpoint: the UK Nutrition and Healthy Life Expectancy (NuLifE) Trial. Through two workshops, along with online discussions and a systematic evidence synthesis, over 40 experts from a range of disciplines came together over 6 months. The workshop reached a consensus and delivered a three-stage plan with the ultimate ambitious aim of providing effective eating behaviour change strategies to address the growing inequalities in the UK and contribute to both a reduced risk of prevalent diet-related chronic disease and an increase in healthy life expectancy.
\end{abstract}

\section{KE Y WORDS}

ageing, eating behaviour, life expectancy, nutrition, randomised controlled trial

\section{INTRODUCTION}

The Medical Research Council (MRC)-National Institute for Health Research (NIHR) Review of Nutrition and Human Health Research 2017 report highlighted the need to 'pull-through' a strong basic science nutrition portfolio in the UK into a population health and economic benefit (MRC, 2017). The UK Nutrition Research Partnership awards, funded by the MRC in partnership with the Biotechnology and Biological Sciences Research Council and NIHR, were established to take forward this agenda, including supporting 'Hot Topic' workshops that would provide novel and robust insights into human nutrition and enhance interdisciplinary collaborations.

The overall objective for this workshop was to progress ideas and planning for a potential UK-wide nutrition primary prevention randomised controlled trial (RCT) with incident disease as the study endpoint: the UK Nutrition and Healthy Life Expectancy (NuLifE) Trial.

This workshop was organised by the principal investigator Anne-Marie Minihane (AMM), along with an early career researcher, co-principal investigator, Jennifer Carter (JC). A working group of key collaborators that helped with the planning of the workshop were John Mathers (JM), Susan Jebb (SJ), Susan

This is an open access article under the terms of the Creative Commons Attribution License, which permits use, distribution and reproduction in any medium, provided the original work is properly cited.

(C) 2021 The Authors. Nutrition Bulletin published by John Wiley \& Sons Ltd on behalf of British Nutrition Foundation 
Fairweather-Tait (SF) and Naveed Sattar (NS), with Amy Jennings (AJ) conducting a systematic review to inform the NuLifE trial design. The workshops were attended by 42 participants from 19 organisations with expertise in nutritional epidemiology, nutritional science, behavioural science, ageing, public health, chronic disease pathology, weight loss, nutrigenomics, health inequalities, clinical trial design and delivery, business strategy, public policy, health economics and digital technology (Appendix A). Senior researchers were encouraged to identify early career researchers to attend.

\section{RATIONALE FOR THE WORKSHOP}

Although beginning to plateau, life expectancy (LE) in the UK has increased 2-3 years every decade for the last century and currently stands at 79 and 83 years for males and females. However, healthy life expectancy (HALE) is not increasing at the same rate, with an increased rate for HALE:LE of 0.8 (ONS, 2018). This is in effect creating one additional year of ill health per person every 15 years. Furthermore, there are large inequalities evident, with 18 years difference in HALE evident in England between the lowest and highest Index of Multiple Deprivation (IMD) groups (ONS, 2018). This trajectory is unsustainable for NHS and social care delivery. The UK Government's 'Ageing Society' Grand Challenge set a mission to increase HALE by 5 years (from 63 to 68 years) by 2035, with the planned NuLifE programme in direct response to this ambitious target (BEIS, 2019).

Suboptimal diet is the number one modifiable determinant of HALE and chronic disease risk globally, and, in the UK, is responsible for $15-20 \%$ of the population attributable fraction of years of life lost (Afshin et al., 2019; Steel et al., 2018). Current UK dietary recommendations and public health policy are based largely on evidence from prospective cohort studies. There is limited evidence from efficacy trials which typically examine the short-term impact of select dietary components or foods on biochemical, functional and imaging-based surrogate markers of disease, as the primary endpoint. The actual impact and size effect of a whole diet intervention on incident disease is completely unknown. In addition, the approaches necessary to implement such an intervention by achieving long-term changes in individual and community eating behaviour are unidentified and untested.

The remit for a NuLifE primary prevention trial is therefore important and timely. The long-term aim of the programme is to establish the impact of a wholediet nutrition intervention on the risk of transition from health to a clinical diagnosis of disease in 'at-risk' UK adults.

\section{AIMS OF THE WORKSHOP}

1. Fully consider the need for and impact of the NuLifE trial.

2. Develop linkages between disciplines (nutrition, trialists, primary and secondary care, health economics, digital health, behavioural science, food industry/retailer, the public) and identify discipline gaps.

3. Advance the research questions and trial design.

4. Develop a plan and timeline for delivering the NuLifE programme and funding strategy.

\section{WORKSHOPS STRUCTURE}

The workshop was delivered as two half-day virtual events, held on the 28th September 2020 and the 17th February 2021. Prior to the first meeting, the following documents were provided to all registered participants to show the relevant policy and scientific background to the NuLifE remit.

- A summary of the workshop bid to the MRC

- Infographic of the UK Eatwell Guide (PHE, 2016a)

- Public Health England's dietary recommendations for the UK 2016 (PHE, 2016b)

- Mortality and life expectancy trends in the UK (Marshall et al., 2019)

- Advancing our Health: Prevention in the 2020 s (Department of Health \& Social Care, 2019)

- World Health Organization: Risk reduction of cognitive decline and dementia 2019 (WHO, 2019)

- Schulze M et al., Food based dietary patterns and chronic disease prevention (Schulze et al., 2018)

- Scheelbeek P, Dangour A et al., Health impacts and environmental footprints of diets that meet the Eatwell Guide recommendations: analyses of multiple UK studies (Scheelbeek et al., 2020)

- Slide sets summarising previous nutrition randomised controlled trials (NU-AGE, CRESSIDA, PREDIMED, Food4Me, MedEx) (Berendsen et al., 2018; CelisMorales et al., 2017; Estruch et al., 2018; Reidlinger et al., 2015; Shannon et al., 2021)

\section{NULIFE WORKSHOP 1}

\section{Key presentations}

The first NuLifE workshop began with an overview of the workshop justification from AMM. To inform the possible disease end-point focus for NULifE, AMM presented the UK LE, HALE and morbidity and mortality statistics. Dementia is the number one cause of mortality in England and Wales accounting for $12.8 \%$ of total deaths in 2017, with dementia and cardiovascular 
diseases collectively responsible for $40 \%$ of total deaths (ONS, 2017). Two-thirds of the UK population are either overweight or obese, with a greater prevalence in those who are most deprived (NHS Digital, 2020). Reflecting on key UK nutrition and dietary guidelines as operationalised in the Eatwell Guide, and current population diet and nutrition data, large proportions of the population are not meeting current dietary targets and there is an evident socio-economic gradient (Bates et al., 2019). In a 2020 analysis using data from 2012 to 2017 in the National Dietary and Nutrition Survey (NDNS), population adherence for nine of the Eatwell Guide recommendations ranged from $7 \%$ to $80 \%$, with the lowest adherence for fibre, oily fish and sugar (Scheelbeek et al., 2020).

To fuel breakout room discussions, and put the subsequent key presentations into perspective, AMM presented some initial thoughts (and related questions) around the potential PICO (i.e. population, intervention, control, outcome) elements of the NuLifE trial (Richardson et al., 1995). For the 'Population' element, the trial would likely need to recruit participants with an 'at-risk' profile in order to achieve the required number of disease cases during the intervention period (but how do we define 'at-risk'?). For the 'Intervention', should we adopt a whole-diet approach, rather than focus on specific nutrients, dietary derived bioactives or select foods/food groups? Should the intervention be bespoke and personalised? Should the trial be a pragmatic, effectiveness trial? For the 'Control' arm, should it be usual care? For the 'Outcome' element, do we focus on incident cardio-metabolic disease, should we include dementia, and should our composite end-point include other major chronic diseases such as diet-sensitive cancers?

Lastly, AMM set out a crude sample size calculation to set the expectations of attendees to the likely scope of the trial. Using event rates from the large prospective UK Biobank study of 0.5 million adults in the UK, with a high-risk population over the age of 55 years, a composite outcome of cardiovascular disease and type 2 diabetes with an event rate of approximately $3 \%$ a year would give a simple two-arm trial over 5 years a power of $90 \%$ to detect a $10 \%$ relative risk reduction if there were approximately 16000 participants (UK Biobank, 2007).

The following speakers and breakout room discussions expanded on these key elements of trial design and the necessary research infrastructure that would be needed for a nutrition trial that was much larger than any that had been previously attempted in the UK (with only a few examples globally; Estruch et al., 2018).

Jane Armitage from the University of Oxford spoke about how new opportunities with digital technologies and data linkage could enhance the ability to run streamlined trials at scale with lower costs and improved quality. Giving examples from the largescale ORION-4 and ASCEND trials (ClinicalTrials.gov Identifier: NCT03705234; NCT00135226), she highlighted the importance of simple inclusion criteria; and the use of electronic health records to identify large numbers of participants, screen and consent them efficiently, and follow them up more completely for a wide range of events (Mafham et al., 2020).

Falko Sniehotta from the University of Newcastle gave a summary of the particular challenges of

TA B LE 1 Summary of Population, Intervention, Control, Outcome (PICO) elements discussed during breakout rooms in NuLifE workshop 1

\begin{tabular}{|c|c|}
\hline PICO breakout room & Main discussion points \\
\hline Intervention/Control & $\begin{array}{l}\text { - A whole-diet approach (e.g. Eatwell Guide) } \\
\text { - Consideration of sustainability } \\
\text { - Personalised tailoring of intervention elements with web-based tools } \\
\text { - Involvement of retailers } \\
\text { - Consideration of difficulties that takeaway food differs across the country, and general difficulties } \\
\text { of randomisation in a whole-diet approach } \\
\text { - Control group is usual care for high-risk groups }\end{array}$ \\
\hline Outcome & $\begin{array}{l}\text { - Composite outcome to increase number of events } \\
\text { - Need a clear causal pathway targeted by nutrition over a 5-year period } \\
\text { - Previous nutrition efficacy trials have shown effects on intermediate mechanisms for } \\
\text { cardiometabolic diseases like cardiovascular disease and diabetes } \\
\text { - Need a different outcome for an interim pilot study, such as blood pressure, that would } \\
\text { demonstrate efficacy of the intervention quickly } \\
\text { - What to do about weight loss? Is this an outcome to aim for, or would it confuse the picture? }\end{array}$ \\
\hline Study design & $\begin{array}{l}\text { - Effectiveness or efficacy trial? } \\
\text { - Factorial design with personalised tailoring }\end{array}$ \\
\hline
\end{tabular}


TABLE 2 Evidence synthesis of randomised controlled trials using behaviour change to improve diet in the last 5 years

\begin{tabular}{|c|c|c|c|c|}
\hline Author & Year & Intervention groups & Participants & Duration \\
\hline Cho et al. (Cho et al., 2020) & 2020 & $\begin{array}{l}\text { 1. nonuser group (control), } \\
\text { 2. app-based diet and exercise self-logging } \\
\text { group (app only) } \\
\text { 3. app-based self-logging and personalised } \\
\text { coaching }\end{array}$ & $\begin{array}{l}30-59 \text { years } \\
\text { two metabolic abnormalities } \\
n=129\end{array}$ & 6 months \\
\hline $\begin{array}{l}\text { Yubero-Serrano et al. (Delgado-Lista et al., } \\
\text { 2016; Yubero-Serrano et al., 2020) } \\
\text { [CORDIOPREV] }\end{array}$ & 2020 & $\begin{array}{l}\text { 1. Mediterranean Diet } \\
\text { 2. Low-fat diet }\end{array}$ & $\begin{array}{l}>20 \&<76 \text { years, } \\
\text { established heart disease } \\
\quad \text { without clinical events in the } \\
\quad \text { last } 6 \text { months } \\
n=1002\end{array}$ & 7 years \\
\hline Rijnaats et al. (Rijnaarts et al., 2020) & 2020 & $\begin{array}{l}\text { 1. Personalised dietary advice (PDA) } \\
\text { 2. General advice (GA) }\end{array}$ & $\begin{array}{l}>18 \text { years } \\
\text { Apparently healthy } \\
\text { Low fibre intake } \\
n=246\end{array}$ & 6 weeks \\
\hline $\begin{array}{l}\text { Hackshaw-McGeagh et al. (Hackshaw- } \\
\text { McGeagh et al., 2019) } \\
{[\text { PrEVENT] }}\end{array}$ & 2019 & $\begin{array}{l}\text { 1. Plant based diet [Fruit/veg (FV) and low } \\
\text { dairy] } \\
\text { 2. Lycopene } \\
\text { 3. Control }\end{array}$ & $\begin{array}{l}\text { Males with prostrate cancer } \\
n=81\end{array}$ & 6 months \\
\hline Kushida et al. (Kushida et al., 2019) & 2019 & $\begin{array}{l}\text { 1. } 1975 \text { Japanese diet (JD) } \\
\text { 2. Modern Diet (MD) }\end{array}$ & $\begin{array}{l}20-30 \text { years } \\
\text { Healthy } \\
n=32\end{array}$ & 4 weeks \\
\hline $\begin{array}{l}\text { Piernas-Sanchez et al. (Piernas et al., } \\
\text { 2020; Piernas et al., 2019) } \\
\text { [PC-SHOP] }\end{array}$ & 2019 & $\begin{array}{l}\text { 1. Control } \\
\text { 2. Health professional advice (HPA) } \\
\text { 3. HPA and grocery shopping feedback }\end{array}$ & $\begin{array}{l}>18 \text { years } \\
\text { Raised LDL-C } \\
n=113\end{array}$ & 3 months \\
\hline $\begin{array}{l}\text { Duś-Żuchowska et al. (Duś-Żuchowska } \\
\text { et al., 2018) }\end{array}$ & 2018 & $\begin{array}{l}\text { 1. Mediterranean Diet } \\
\text { 2. Central European Diet }\end{array}$ & $\begin{array}{l}\text { Post-menopausal } \\
n=144\end{array}$ & 16 weeks \\
\hline Katsagoni et al. (Katsagoni et al., 2018) & 2018 & $\begin{array}{l}\text { 1. Control } \\
\text { 2. Mediterranean diet (MD) } \\
\text { 3. Mediterranean lifestyle (ML) }\end{array}$ & $\begin{array}{l}\text { 18-65 } \\
\text { With non-alcoholic fatty liver } \\
\quad \text { disease } \\
n=63\end{array}$ & 6 months \\
\hline Kazemi et al. (Kazemi et al., 2018) & 2018 & $\begin{array}{l}\text { 1. Pulse-based diet } \\
\text { 2. Healthy control diet }\end{array}$ & $\begin{array}{l}\text { Polycystic ovary syndrome } \\
n=61\end{array}$ & 16 weeks \\
\hline Krishnan et al. (Krishnan et al., 2018) & 2018 & $\begin{array}{l}\text { 1. Typical American Diet (TAD) } \\
\text { 2. Dietary Guidelines America diet (DGA) }\end{array}$ & $\begin{array}{l}\text { Overweight to obese women, } \\
\text { less than } 150 \mathrm{~min} / \text { week } \\
\text { physical activity } \\
\geq 1 \text { cardiometabolic risk factor } \\
n=52\end{array}$ & 8 weeks \\
\hline Properzi et al. (Properzi et al., 2018) & 2018 & $\begin{array}{l}\text { 1. Mediterranean Diet (MD) } \\
\text { 2. Low-fat diet }\end{array}$ & $\begin{array}{l}\text { Non-alcoholic fatty liver disease } \\
n=51\end{array}$ & 12 weeks \\
\hline $\begin{array}{l}\text { Winkvist et al. (Winkvist et al., 2018; Vadell } \\
\text { et al., 2020) }\end{array}$ & 2018 & $\begin{array}{l}\text { 1. Anti-inflammatory diet } \\
\text { 2. Typical diet }\end{array}$ & $\begin{array}{l}\text { Rheumatoid arthritis } \geq 2 \text { years, } \\
18-75 \text { years } \\
n=50\end{array}$ & $\begin{array}{l}\text { 10-week } \\
\text { (cross- } \\
\text { over) }\end{array}$ \\
\hline $\begin{array}{l}\text { Jayawardena et al. (Jayawardena et al., } \\
\text { 2017) }\end{array}$ & 2017 & $\begin{array}{l}\text { 1. Control } \\
\text { 2. 'Plate model' Intervention }\end{array}$ & $\begin{array}{l}\text { Post-myocardial infarction } \\
n=120\end{array}$ & 12 weeks \\
\hline $\begin{array}{l}\text { Koutoukidis et al. (Koutoukidis et al., 2017; } \\
\text { Koutoukidis et al., 2019) [DEUS] }\end{array}$ & 2017 & $\begin{array}{l}\text { 1. Control } \\
\text { 2. Shape-up intervention }\end{array}$ & $\begin{array}{l}\text { Women }>18 \text { years } \\
\text { Endometrial cancer } \\
n=54\end{array}$ & 8 weeks \\
\hline
\end{tabular}




\begin{tabular}{|c|c|c|c|}
\hline Outcomes & Behaviour change components & Dietary change & Results \\
\hline $\begin{array}{l}\text { Blood pressure, weight, } \\
\text { waist circumference, } \\
\text { body fat, HOMA-IR } \\
\text { and lipids }\end{array}$ & $\begin{array}{l}\text { Personalised feedback (Group 3) } \\
\text { Self-monitoring (Group } 2+3)\end{array}$ & Not reported & $\begin{array}{l}\text { Personalised feedback not } \\
\text { more effective than } \\
\text { self-monitoring }\end{array}$ \\
\hline Cardiovascular events & $\begin{array}{l}\text { Personalised interviews, group education } \\
\text { sessions and food provision to both } \\
\text { groups }\end{array}$ & $\begin{array}{l}\text { Differences in adherence to the } 14 \text { items of } \\
\text { the MEDAS after } 1 \text { year }\end{array}$ & Study ongoing \\
\hline Fibre intake & Personalised advice (web-based service) & $\begin{array}{l}\text { Participants in the PDA group were } \\
\text { more likely to adhere to fibre } \\
\text { recommendations }\end{array}$ & - \\
\hline $\begin{array}{l}\text { Adherence (based as } \\
\qquad 90 \% \text { of time) }\end{array}$ & $\begin{array}{l}\text { Printed instructions (group 1) } \\
\text { Supplements (group 2) }\end{array}$ & $\begin{array}{l}40 \% \text { adhered to } \mathrm{FV} \\
72 \% \text { adhered to dairy } \\
79 \% \text { adhered lycopene }\end{array}$ & - \\
\hline Change in gut microbiota & $\begin{array}{l}\text { Three meals daily pre-prepared food (both } \\
\text { groups) }\end{array}$ & Not reported & $\begin{array}{l}\text { Taxa significantly changed } \\
\text { after consumption of JD }\end{array}$ \\
\hline Saturated fat intake (SFA) & $\begin{array}{l}\text { Personalised feedback (Group } 3 \text { ) } \\
\text { Advice session (COM-B behaviour change } \\
\quad \text { wheel) (Group } 2 \text { and } 3 \text { ) }\end{array}$ & $\begin{array}{l}\text { No difference in SFA intake or food } \\
\text { purchasing between groups }\end{array}$ & $\begin{array}{l}\text { No difference in lipid profiles } \\
\text { compared to control }\end{array}$ \\
\hline $\begin{array}{l}\text { Asymmetrical } \\
\text { dimethylarginine } \\
\text { (ADMA) and C- } \\
\text { reactive protein } \\
\text { (hs-CRP) }\end{array}$ & $\begin{array}{l}\text { Pre-portioned main meals (covering } 35 \% \text { of } \\
\text { energy) delivered (both groups) }\end{array}$ & Not reported & $\begin{array}{l}\text { No between-group differences } \\
\text { in ADMA or hs-CRP }\end{array}$ \\
\hline $\begin{array}{l}\text { Liver enzymes (ALP and } \\
\qquad \text { ALT) }\end{array}$ & $\begin{array}{l}\text { MD and ML } 7 \times 1 \mathrm{~h} \text { group sessions based } \\
\text { on goal setting theory }\end{array}$ & $\begin{array}{l}\text { ML and MD improved MD adherence (FFQ } \\
\text { and } 24-\mathrm{h} \text { recall) }\end{array}$ & $\begin{array}{l}\text { MI - improved ALT and liver } \\
\text { stiffness }\end{array}$ \\
\hline $\begin{array}{l}\text { Liver stiffness } \\
\text { Weight loss } \\
\text { Adherence }\end{array}$ & $\mathrm{ML}-$ diet + activity and sleep & & ML and MD - weight loss \\
\hline $\begin{array}{l}\text { Cardiometabolic } \\
\text { measures }\end{array}$ & $\begin{array}{l}\text { Two meals (i.e., lunch and dinner) were } \\
\text { supplied daily for participants in the } \\
\text { pulse-based diet group }\end{array}$ & $\begin{array}{l}\text { Differences in fibre and micronutrient } \\
\text { intakes between groups (24-h recalls) }\end{array}$ & $\begin{array}{l}\text { Pulse-based diet decreased } \\
\text { total insulin AUC, levels of } \\
\text { LDL-C, TG, TC/HDL-C ratio, } \\
\text { diastolic blood pressure, } \\
\text { and increased HDL-C } \\
\text { compared to control diet }\end{array}$ \\
\hline $\begin{array}{l}\text { Glucose homeostasis } \\
\text { and fasting lipids }\end{array}$ & All meals provided & $\begin{array}{c}30 \pm 35(10.4 \% \pm 0.1 \% \text { deviation }) \text { instances } \\
\text { of reported deviance from full dietary }\end{array}$ & $\begin{array}{l}\text { No between-group differences } \\
\text { in primary outcomes }\end{array}$ \\
\hline
\end{tabular}

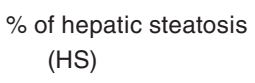

Printed instructions (group 1)

upplements (group 2)

(both groups)

Natural muesli and low-fat snack bars for the low-fat diet

Personalised dietary advice (both groups)

Food provision (both groups) equivalent $50 \%$ of the daily intake during 5 weekdays

Personalised advice

Group sessions $39 \pm 31(13.9 \% \pm 0.1 \%)$ instances of reported deviance in the TAD group

Dietary change achieved in both groups (Diet History)

\section{more likely to adhere to fibre}

$40 \%$ adhered to $\mathrm{FV}$

$72 \%$ adhered to dairy

Not reported

difference in SFA intake or food

and $\mathrm{MD}$ improved MD adherence (FFQ

Intakes of fibre, EPA, and DHA were considerably higher during the intervention period (3-d diet record)

Not reported

$77 \%$ adhered to intervention (AHEI results not reported)
No significant differences between groups

Weight reduction relative to control. No change in BP or lipids

Adherence improved but not QoL 
TABLE 2 (Continued)

\begin{tabular}{|c|c|c|c|c|}
\hline Author & Year & Intervention groups & Participants & Duration \\
\hline Ananad et al. (Anand et al., 2016) & 2016 & $\begin{array}{l}\text { 1. Control } \\
\text { 2. Digital health intervention }\end{array}$ & $\begin{array}{l}>30 \text { years } \\
\text { South Asian } \\
n=343\end{array}$ & 1 year \\
\hline Wong et al. (Wong et al., 2016) & 2016 & $\begin{array}{l}\text { 1. Control } \\
\text { 2. Intervention }\end{array}$ & $\begin{array}{l}40-70 \text { years } \\
\text { Hypertension } \\
n=556\end{array}$ & 1 year \\
\hline
\end{tabular}

Abbreviations: AHEI, alternative healthy eating index; ALP, Alkaline phosphatase; ALT, alanine aminotransferase; AUC, area under the curve; DHA, docosahexaenoic acid; EPA, eicosapentaenoic acid; FFQ, food frequency questionnaire; HDL-C, high-density lipoprotein cholesterol; HOMA-IR, Homeostatic Model Assessment for Insulin Resistance; LDL-C, low-density lipoprotein-cholesterol; MEDAS, Mediterranean Diet Adherence Screener; TC, total cholesterol; TG, triglyceride.

behavioural interventions at scale, with a focus on fidelity, adherence, effectiveness and efficacy. He summarised that a whole systems approach was needed for complex behavioural interventions, which complicated the evaluation and interpretation of the trial result, but would be more likely to facilitate maintenance of changed behaviour over time and improve health outcomes.

Finally, Paul Aveyard from the University of Oxford spoke about the trial design options. This started with a reminder of the MRC Framework for complex intervention development and reinforcing the value of defining the behavioural theory underpinning the putative intervention (Craig et al., 2008). Given this is a trial aiming for a long-term health outcome, it is vital to ensure the intervention had the best chance of achieving sustained dietary change. The presentation then passed on to novel trial designs that may be employed in early-stage development work, such as the multiphase optimisation strategy trial design, that can help determine the effect of particular components of an intervention, and the value of adaptive designs in finding ways to maximise the benefit of a behavioural support programme (Wyrick et al., 2014). Finally, he presented an explanatory-pragmatic trial continuum to fuel debate about which end of the spectrum we would want to situate this work.

\section{Breakout rooms and general discussion}

Four breakout rooms then discussed the PICO elements on the study design in depth, and fed back to the entire group their main points. See Table 1 for a summary of the discussed PICO elements.

When the breakout rooms fed back to the final discussion, a consensus emerged that there was a need and a will to proceed with the NuLifE programme. It was noted that it was especially important to consider how such a trial might help address health inequalities, perhaps by recruiting specifically in areas of high deprivation. The other main area of discussion was whether NuLifE would be an efficacy trial, focussed on answering the question of the strength of the impact of a healthy diet on the risk of disease outcomes; or an effectiveness trial, demonstrating the impact of a pragmatic dietary intervention on a representative sample of the UK.

Subsequently between workshops, comments were sought online on three possible study designs.

1. An individual-level efficacy (explanatory) RCT aiming to change dietary behaviours and reduce incident disease in UK adults.

2. An individual-level effectiveness (pragmatic) RCT aiming to change dietary behaviours and reduce incident disease in UK adults.

3. A population-level cluster (area/town/city) RCT aiming to influence structural (social, cultural, economic, geographical and other environmental) determinants of eating behaviour, improving eating behaviour and nutrient status in UK adults, and reducing the risk of incident disease in UK adults.

\section{NULIFE WORKSHOP 2}

At the start of the second NuLifE workshop, AMM began with a summary of the first workshop and the online working documents. The online working document of potential study designs between sessions had reached an agreement that there was insufficient justification to proceed with an explanatory RCT (\#1 above) for the following reasons:

- To run a true whole-diet efficacy RCT with long-term outcomes, we would need to be very confident of the ability to implement an intervention with high fidelity, and with a compliant (pre-screened, selected and monitored) population group, to have the power to detect outcomes. It would be practically very challenging to get the compliance needed for the level of certainty required.

- Furthermore, such an approach would likely divert attention from populations where there is greatest need (i.e. participants in communities with high levels of deprivation). 


\begin{tabular}{lcl}
\hline Outcomes & Behaviour change components & Dietary change \\
\hline $\begin{array}{l}\text { Myocardial infarction risk } \\
\text { score }\end{array}$ & $\begin{array}{c}\text { Stages of change motivational message } \\
\text { and health tips every } 2 \text { weeks }\end{array}$ & Not reported \\
$\begin{array}{l}\text { 10-year cardiovascular } \\
\text { risk }\end{array}$ & $\begin{array}{c}\text { Counselling session }(1 \times 25 \text { min }) \text { and } \\
\text { individualised meal plans }\end{array}$ & Not reported \\
\end{tabular}

- An efficacy trial would need to be followed by effectiveness trials if the results are going to inform public health policy.

- As a result, the higher priority and best use of resources would be to conduct a pragmatic trial in deprived communities where the poorest adherence to dietary guidelines is evident. Such a trial is likely to be more informative and impactful than a similarly sized trial in the general population.

Although there was a strong rationale for a cluster intervention approach (\#3 above), which focussed on contextual modulators of eating behaviour, the development of such an intervention appeared currently unrealistic as it would be reliant on enactment of several fiscal, food and health-related policy changes; and a much greater understanding of the relative structural determinants of food purchasing and eating behaviour than is currently available.

The consensus was clear, that NuLifE would proceed with planning an effectiveness (pragmatic) trial focussed on examining the impact of an eating behaviour intervention on incident disease in communities with a high score on the IMD.

Such an approach is aligned with the public health policy need as reflected in:

1. the UK Government Ageing Society Grand Challenge mission (BEIS, 2019);

2. the Public Health England's Strategy 2020-2025, around healthy inequalities and healthy ageing (PHE, 2019);

3. current health and behaviour inequalities, aggravated and highlighted by the COVID-19 pandemic and its impact on COVID-19 prognosis (Bambra et al., 2020);

4. reports such as Health equity in England: The Marmot review 10 years on (Marmot, 2020).

Prior to the second meeting, the working group agreed that it was clear we were lacking a consensus on the intervention approach for NuLifE. It was decided that we needed an evidence synthesis of eating behaviour interventions to help inform the discussion.

\section{Evidence synthesis of eating behaviour interventions}

Changing eating behaviour is hugely challenging, with numerous social, cultural, economic, environment and geographical variables influencing food purchase and consumption. Prior to workshop 2, a systematic search of the empirical evidence was conducted by AJ (University of East Anglia) to inform the discussion and to establish the evidence for the impact of various interventions on attainment and maintenance of eating behaviour change. Search terms looked for any RCT on diet and disease in adults that did not involve supplements, which was published since 2015; the search was extended to also look for any RCTs on diet conducted in the UK since 2010. Results were excluded if the trials did not involve behavioural change or were lacking diet-only treatment arms (see Appendix B for more details). The following intervention approaches were focussed on and summarised, along with their results:

1. food/meal provision

2. cash incentives, food vouchers, supermarket delivery

3. digital intervention

4. personalisation

5. education and cookery skills

6. Behaviour Change Technique (BCT)-based

7. group sessions and peer support

8. community-based intervention.

Results from trials run in the last 5 years are summarised in Table 2 (further results are in Appendix B). Many trials were conducted in healthy individuals who were not selected on the basis of the quality of their diet and hence many had adequate diets at baseline. A range of dietary components were targeted and, in many cases, an exact definition of dietary improvement was not detailed. It was therefore difficult to conclude if the studies that reported no effect on health outcomes were due to poor adherence or a true lack of effect. With such heterogeneity in the results, it was not possible to reach a consensus on which whole diet intervention 
approaches would be most likely to provide individuals, families and communities with the capability, opportunity and motivation to enact and maintain eating behaviour change. It was also clear that research aimed at enacting dietary behaviour change in deprived communities was particularly scarce.

\section{Presentations and breakout rooms focussed on intervention}

The presentations and breakout room discussions for the second workshop all focussed around defining an effective eating behaviour intervention. First, spokespeople from previous whole-diet interventions (JM from Food4Me, AJ from NuAge, Wendy Hall from CRESSIDA, AMM from MedEx) summarised key insights from their studies (details of these studies are summarised in Appendix B).

Breakout rooms chaired by members of the working group (NS, SJ, JC, JM) then discussed the intervention components as a first priority, and the study population or key endpoints as a second priority. Feedback and general discussion amongst the entire group revealed that there was a general enthusiasm for targeting groups with high IMD scores of deprivation as a unique component of NuLife. However, there was also a consensus that the NuLifE trial would need to be conducted in stages in order to achieve its ultimate goal, requiring a strong community co-creation, pilot and feasibility phase in order to proceed with confidence with an eating behaviour intervention strategy which is fit for purpose.

\section{STAGE 1: TAILORING COMPLEX DIETARY INTERVENTIONS TO COMMUNITIES WITH A HIGH INDEX OF MULTIPLE DEPRIVATION}

Stage 1 of the NuLifE programme will be a communitybased (high IMD communities), Patient and Public Involvement informed, project to co-design, develop and test the NuLifE intervention approaches to increase the agency of residents to enact eating behaviour within the Eatwell guidelines. The intervention will be developed based on the MRC Developing and evaluating complex intervention guidelines (Craig et al., 2008). In addition, the intervention will be co-developed and co-produced with organisations such as the Integrated Care Systems, Community Foundations, FoodBanks/ Trussell Trust, community-embedded food retailers (e.g. Co-op/ALDI) and build on existing community assets. Both personalised (to the individual's baseline health and eating behaviour status) and contextual intervention components will be considered, with the ultimate aim to provide individual and communities with the capability, opportunity and motivation to enact healthier eating behaviours which aim to increase HALE and reduce chronic disease onset (Michie et al., 2011).

\section{STAGE 2: ONE-YEAR \\ EFFECTIVENESS TRIAL ON INTERIM END POINT OF BLOOD PRESSURE}

The NuLifE consortium then agreed that Stage 2 of the NuLifE programme would be an interim step to test the effectiveness of a one-year intervention of the NuLifE approach with blood pressure as the primary endpoint. Blood pressure is a robust target due to its strong prognostic value for future cardiovascular diseases, and it is influenced by a wide array of foods and macro- and micro-nutrients and non-nutrient bioactives (Jennings et al., 2019; Ndanuko et al., 2016).

\section{STAGE 3: LARGE-SCALE EFFECTIVENESS PRIMARY PREVENTION RCT}

Finally, Stage 3 would be to run a full effectiveness primary prevention RCT of the NuLifE intervention to assess the effect on incident disease.

\section{CONCLUSION}

We thank the MRC for funding this workshop, which provided the impetus for over 40 experts from a range of disciplines to come together over 6 months. Through two workshops, along with online discussions and a systematic evidence synthesis, the first UK nutrition, primary prevention, effectiveness trial took shape. The workshops delivered a three-stage plan with the ultimate ambitious aim of establishing a multi-disciplinary and multi-agency approach, alongside effective eating behaviour change strategies, to address the growing inequalities in the UK and contribute to a reduced risk of prevalent diet-related chronic disease and increased HALE. Such an approach directly addresses the Government's 'Ageing Society' Grand Challenge to 'ensure that people can enjoy at least 5 extra healthy, independent years of life by 2035 , while narrowing the gap between the experience of the richest and poorest' (BEIS, 2019).

\section{ACKNOWLEDGEMENTS}

JC and AMM drafted the manuscript; JM, SFT, SJ, NS, AJ all assisted with creating, editing and revising the manuscript. 


\section{CONFLICT OF INTEREST}

No conflicts of interest.

\section{ORCID}

Jennifer Carter (10) https://orcid.

org/0000-0002-5298-4844

Anne-Marie Minihane (1) https://orcid.

org/0000-0001-9042-4226

\section{REFERENCES}

Afshin, A., Sur, P.J., Fay, K.A., Cornaby, L., Ferrara, G., Salama, J.S. et al. (2019) Health effects of dietary risks in 195 countries, 1990-2017: a systematic analysis for the Global Burden of Disease Study 2017. The Lancet, 393, 1958-1972.

Anand, S.S., Samaan, Z., Middleton, C., Irvine, J., Desai, D., Schulze, K.M. et al. (2016) A digital health intervention to lower cardiovascular risk: a randomized clinical trial. JAMA Cardiology, 1, 601-606.

Bambra, C., Riordan, R., Ford, J. \& Matthews, F. (2020) The COVID-19 pandemic and health inequalities. Journal of Epidemiology and Community Health, 74, 964-968.

Bates, B., Collins, D., Cox, L. \& NDNS team. (2019) National Diet and Nutrition Survey Years 1 to 9 of the Rolling Programme (2008/2009-2016/2017): time trend and income analyses. London, UK: Public Health England; p. 56.

Berendsen, A., van de Rest, O., Feskens, E., Santoro, A., Ostan, R., Pietruszka, B. et al. (2018) Changes in dietary intake and adherence to the NU-AGE diet following a one-year dietary intervention among european older adults-results of the NU-AGE randomized trial. Nutrients, 10, 1905.

Celis-Morales, C., Livingstone, K.M., Marsaux, C.F., Macready, A.L., Fallaize, R., Donovan, C.B. et al. (2017) Effect of personalized nutrition on health-related behaviour change: evidence from the Food4me European randomized controlled trial. International Journal of Epidemiology, 46, 578-588.

Cho, S.M.J., Lee, J.H., Shim, J.-S., Yeom, H., Lee, S.J., Jeon, Y.W. et al. (2020) Effect of smartphone-based lifestyle coaching app on community-dwelling population with moderate metabolic abnormalities: randomized controlled trial. Journal of Medical Internet Research, 22, e17435.

Craig, P., Dieppe, P., Macintyre, S., Michie, S., Nazareth, I. \& Petticrew, M. (2008) Developing and evaluating complex interventions: the new Medical Research Council guidance. British Medical Journal, 337, a1655.

Delgado-Lista, J., Perez-Martinez, P., Garcia-Rios, A., Alcala-Diaz, J.F., Perez-Caballero, A.I., Gomez-Delgado, F. et al. (2016) CORonary Diet Intervention with Olive oil and cardiovascular PREVention study (the CORDIOPREV study): Rationale, methods, and baseline characteristics: a clinical trial comparing the efficacy of a Mediterranean diet rich in olive oil versus a low-fat diet on cardiovascular disease in coronary patients. American Heart Journal, 177, 42-50.

Department for Business, Energy \& industrial Strategy (BEIS). (2019) The grand challenges. London. Accessed from https:// www.gov.uk/government/publications/industrial-strategy-thegrand-challenges/industrial-strategy-the-grand-challenges [Accessed 23rd October 2019].

Department of Health and Social Care. (2019) Advancing our health: prevention in the 2020s. Crown Copyright: London. Accessed from https://www.gov.uk/government/consultations/advancingour-health-prevention-in-the-2020s [Accessed 10 October 2019].

Duś-Żuchowska, M., Bajerska, J., Krzyżanowska, P., Chmurzyńska, A., Miśkiewicz-Chotnicka, A., Muzsik, A. \& et al. (2018) The Central European diet as an alternative to the Mediterranean diet in atherosclerosis prevention in postmenopausal obese women with a high risk of metabolic syndrome - a randomized nutrition-al trial. Acta Scientiarum Polonorum, Technologia Alimentaria, 17, 399-407.

Estruch, R., Ros, E., Salas-Salvadó, J., Covas, M.-I., Corella, D., Arós, F. et al. (2018) Primary prevention of cardiovascular disease with a Mediterranean diet supplemented with extra-virgin olive oil or nuts. New England Journal of Medicine, 378, e34.

Hackshaw-McGeagh, L.E., Penfold, C., Shingler, E., Robles, L.A., Perks, C.M., Holly, J.M.P. et al. (2019) Phase II randomised control feasibility trial of a nutrition and physical activity intervention after radical prostatectomy for prostate cancer. British Medical Journal Open, 9, e029480.

Jayawardena, R., Fernando, P., Lokunarangoda, N. \& Pathirana, A.K. (2017) Effects of the "plate model" as part of dietary intervention on modification of selected cardiometabolic risk factors in post-myocardial infarction patients: study protocol for a randomized controlled trial. Trials, 18, 314.

Jennings, A., Berendsen, A.M., de Groot, L.C.P.G.M., Feskens, E.J.M., Brzozowska, A., Sicinska, E. et al. (2019) Mediterraneanstyle diet improves systolic blood pressure and arterial stiffness in older adults. Hypertension, 73, 578-586.

Katsagoni, C.N., Papatheodoridis, G.V., Ioannidou, P., Deutsch, M., Alexopoulou, A., Papadopoulos, N. et al. (2018) Improvements in clinical characteristics of patients with non-alcoholic fatty liver disease, after an intervention based on the Mediterranean lifestyle: a randomised controlled clinical trial. British Journal of Nutrition, 120, 164-175.

Kazemi, M., McBreairty, L., Chizen, D., Pierson, R., Chilibeck, P. \& Zello, G. (2018) A comparison of a pulse-based diet and the therapeutic lifestyle changes diet in combination with exercise and health counselling on the cardio-metabolic risk profile in women with polycystic ovary syndrome: a randomized controlled trial. Nutrients, 10, 1387.

Koutoukidis, D.A., Beeken, R.J., Manchanda, R., Michalopoulou, M., Burnell, M., Knobf, M.T. et al. (2017) Recruitment, adherence, and retention of endometrial cancer survivors in a behavioural lifestyle programme: the Diet and Exercise in Uterine Cancer Survivors (DEUS) parallel randomised pilot trial. British Medical Journal Open, 7, e018015.

Koutoukidis, D.A., Beeken, R.J., Manchanda, R., Burnell, M., Ziauddeen, N., Michalopoulou, M. et al. (2019) Diet, physical activity, and health-related outcomes of endometrial cancer survivors in a behavioral lifestyle program: the Diet and Exercise in Uterine Cancer Survivors (DEUS) parallel randomized controlled pilot trial. International Journal of Gynecological Cancer, 29, 531-540.

Krishnan, S., Adams, S.H., Allen, L.H., Laugero, K.D., Newman, J.W., Stephensen, C.B. et al. (2018) A randomized controlledfeeding trial based on the Dietary Guidelines for Americans on cardiometabolic health indexes. American Journal of Clinical Nutrition, 108, 266-278.

Kushida, M., Sugawara, S., Asano, M., Yamamoto, K., Fukuda, S. \& Tsuduki, T. (2019) Effects of the 1975 Japanese diet on the gut microbiota in younger adults. Journal of Nutritional Biochemistry, 64, 121-127.

Mafham, M.M., Bowman, L.J., Haynes, R.J. \& Armitage, J.M. (2020) Streamlined mail-based methods for large randomised trials: lessons learnt from the ASCEND study. Diabetologia, 63, 898-905.

Marmot, M. (2020) Health equity in England: the Marmot review 10 years on. British Medical Journal, 368, 1-4.

Marshall, L., Finch, D., Cairncross, L. \& Bibby, J. (2019) Mortality and life expectancy trends in the UK: stalling progress. London: The Health Foundation. Accessed from https://www.health.org. uk/publications/reports/mortality-and-life-expectancy-trendsin-the-uk [Accessed 17 August 2020].

Michie, S., van Stralen, M.M. \& West, R. (2011) The behaviour change wheel: a new method for characterising and designing 
behaviour change interventions. Implementation Science, 6, 42.

MRC, National Institute for Health Research \& Office for Strategic Coordination of Health Research. (2017) Review of Nutrition and Human Health Research. Accessed from https://mrc.ukri. org/documents/pdf/review-of-nutrition-and-human-health/ [Accessed 10 October 2019].

Ndanuko, R.N., Tapsell, L.C., Charlton, K.E., Neale, E.P. \& Batterham, M.J. (2016) Dietary patterns and blood pressure in adults: a systematic review and meta-analysis of randomized controlled trials. Advances in Nutrition, 7, 76-89.

NHS Digital. (2020) Health Survey for England 2019. Accessed from https://digital.nhs.uk/data-and-information/publicatio ns/statistical/health-survey-for-england/2019 [Accessed 10 September 2020].

Office for National Statistics (ONS). (2017) Death registration summary tables-England and Wales, 2017. Accessed from https:// www.ons.gov.uk/peoplepopulationandcommunity/birthsdeat hsandmarriages/deaths/datasets/deathregistrationssummary tablesenglandandwalesreferencetables [Accessed 5 October 2019].

Office for National Statistics (ONS). (2018) Health state life expectancies, UK: 2015 to 2017. London. Accessed from https:// www.ons.gov.uk/ [accessed 05 September 2020].

Piernas, C., Aveyard, P., Lee, C., Tsiountsioura, M., Noreik, M., Astbury, N.M. et al. (2020) Evaluation of an intervention to provide brief support and personalized feedback on food shopping to reduce saturated fat intake (PC-SHOP): a randomized controlled trial. PLoS Med, 17, e1003385.

Piernas, C., Tsiountsioura, M., Astbury, N.M., Madigan, C., Aveyard, P. \& Jebb, S.A. (2019) Primary Care SHOPping intervention for cardiovascular disease prevention (PC-SHOP): protocol for a randomised controlled trial to reduce saturated fat intake. British Medical Journal Open, 9, e027035.

Properzi, C., O'Sullivan, T.A., Sherriff, J.L., Ching, H.L., Jeffrey, G.P., Buckley, R.F. et al. (2018) Ad libitum Mediterranean and low-fat diets both significantly reduce hepatic steatosis: a randomized controlled trial. Hepatology, 68, 1741-1754.

Public Health England (PHE). (2016) Government recommendations for energy and nutrients for males and females aged 1-18 years and 19+ years. Accessed from https://assets.publishing. service.gov.uk/government/uploads/system/uploads/attac hment_data/file/618167/government_dietary_recommenda tions.pdf [accessed 14 September 2020].

Public Health England (PHE). (2016) The Eatwell Guide: helping you eat a healthy, balanced diet. Accessed from https://www.gov. uk/government/publications/the-eatwell-guide [Accessed 14 September 2020].

Public Health England (PHE). (2019) PHE Strategy 2020-2025. Accessed from https://assets.publishing.service.gov.uk/gover nment/uploads/system/uploads/attachment_data/file/831562/ PHE_Strategy_2020-25.pdf [Accessed 7 December 2020].

Reidlinger, D.P., Darzi, J., Hall, W.L., Seed, P.T., Chowienczyk, P.J. \& Sanders, T.A.B. (2015) How effective are current dietary guidelines for cardiovascular disease prevention in healthy middleaged and older men and women? A randomized controlled trial. American Journal of Clinical Nutrition, 101, 922-930.

Richardson, W.S., Wilson, M.C., Nishikawa, J. \& Hayward, R.S. (1995) The well-built clinical question: a key to evidence-based decisions. ACP Journal Club, 123, A12-A13.

Rijnaarts, I., de Roos, N.M., Wang, T., Zoetendal, E.G., Top, J., Timmer, M. et al. (2020) Increasing dietary fibre intake in healthy adults using personalised dietary advice compared with general advice: a single-blind randomised controlled trial. Public Health Nutrition, 24, 1117-1128.

Scheelbeek, P., Green, R., Papier, K., Knuppel, A., Alae-Carew, C., Balkwill, A. et al. (2020) Health impacts and environmental footprints of diets that meet the Eatwell Guide recommendations: analyses of multiple UK studies. British Medical Journal Open, 10, e037554.

Schulze, M.B., Martínez-González, M.A., Fung, T.T., Lichtenstein, A.H. \& Forouhi, N.G. (2018) Food based dietary patterns and chronic disease prevention. British Medical Journal, 361, 1-6.

Shannon, O.M., Lee, V., Bundy, R., Gillings, R., Jennings, A., Stephan, B. et al. (2021) Feasibility and acceptability of a multidomain intervention to increase Mediterranean diet adherence and physical activity in older UK adults at risk of dementia: protocol for the MedEx-UK randomised controlled trial. British Medical Journal Open, 11, e042823.

Steel, N., Ford, J.A., Newton, J.N., Davis, A.C.J., Vos, T., Naghavi, M. et al. (2018) Changes in health in the countries of the UK and 150 English Local Authority areas 1990-2016: a systematic analysis for the Global Burden of Disease Study 2016. The Lancet, 392, 1647-1661.

UK Biobank. (2007) UK Biobank: protocol for a large-scale prospective epidemiological resource. Vol. 2016. UK Biobank. https:// www.ukbiobank.ac.uk/media/gnkeyh2q/study-rationale.pdf

Vadell, A.K.E., Bärebring, L., Hulander, E., Gjertsson, I., Lindqvist, H.M. \& Winkvist, A. (2020) Anti-inflammatory Diet In Rheumatoid Arthritis (ADIRA) - a randomized, controlled crossover trial indicating effects on disease activity. American Journal of Clinical Nutrition, 111, 1203-1213.

Winkvist, A., Bärebring, L., Gjertsson, I., Ellegård, L. \& Lindqvist, H.M. (2018) A randomized controlled cross-over trial investigating the effect of anti-inflammatory diet on disease activity and quality of life in rheumatoid arthritis: the Anti-inflammatory Diet In Rheumatoid Arthritis (ADIRA) study protocol. Nutrition Journal, 17, 44.

Wong, M.C.S., Wang, H.H.X., Kwan, M.W.M., Li, S.T.S., Liang, M., Fung, F.D.H. et al. (2016) The effectiveness of Dietary Approaches to Stop Hypertension (DASH) counselling on estimated 10-year cardiovascular risk among patients with newly diagnosed grade 1 hypertension: a randomised clinical trial. International Journal of Cardiology, 224, 79-87.

World Health Organization (WHO). (2019) Risk reduction of cognitive decline and dementia: WHO guidelines. Geneva: World Health Organization.

Wyrick, D.L., Rulison, K.L., Fearnow-Kenney, M., Milroy, J.J. \& Collins, L.M. (2014) Moving beyond the treatment package approach to developing behavioral interventions: addressing questions that arose during an application of the Multiphase Optimization Strategy (MOST). Translational Behavioral Medicine, 4, 252-259.

Yubero-Serrano, E.M., Fernandez-Gandara, C., Garcia-Rios, A., Rangel-Zuñiga, O.A., Gutierrez-Mariscal, F.M., Torres-Peña, J.D. et al. (2020) Mediterranean diet and endothelial function in patients with coronary heart disease: an analysis of the CORDIOPREV randomized controlled trial. PLoS Med, 17, e1003282.

How to cite this article: Carter, J., Mathers, J., Fairweather-Tait, S., Jebb, S., Sattar, N., Jennings, A. et al (2021) Medical Research Council Hot Topic workshop report: Planning a UK Nutrition and Healthy Life Expectancy Trial. Nutrition Bulletin, 46, 395-408. https://doi. org/10.1111/nbu.12516 


\section{APPENDIX A}

\section{WORKSHOP ATTENDEES}

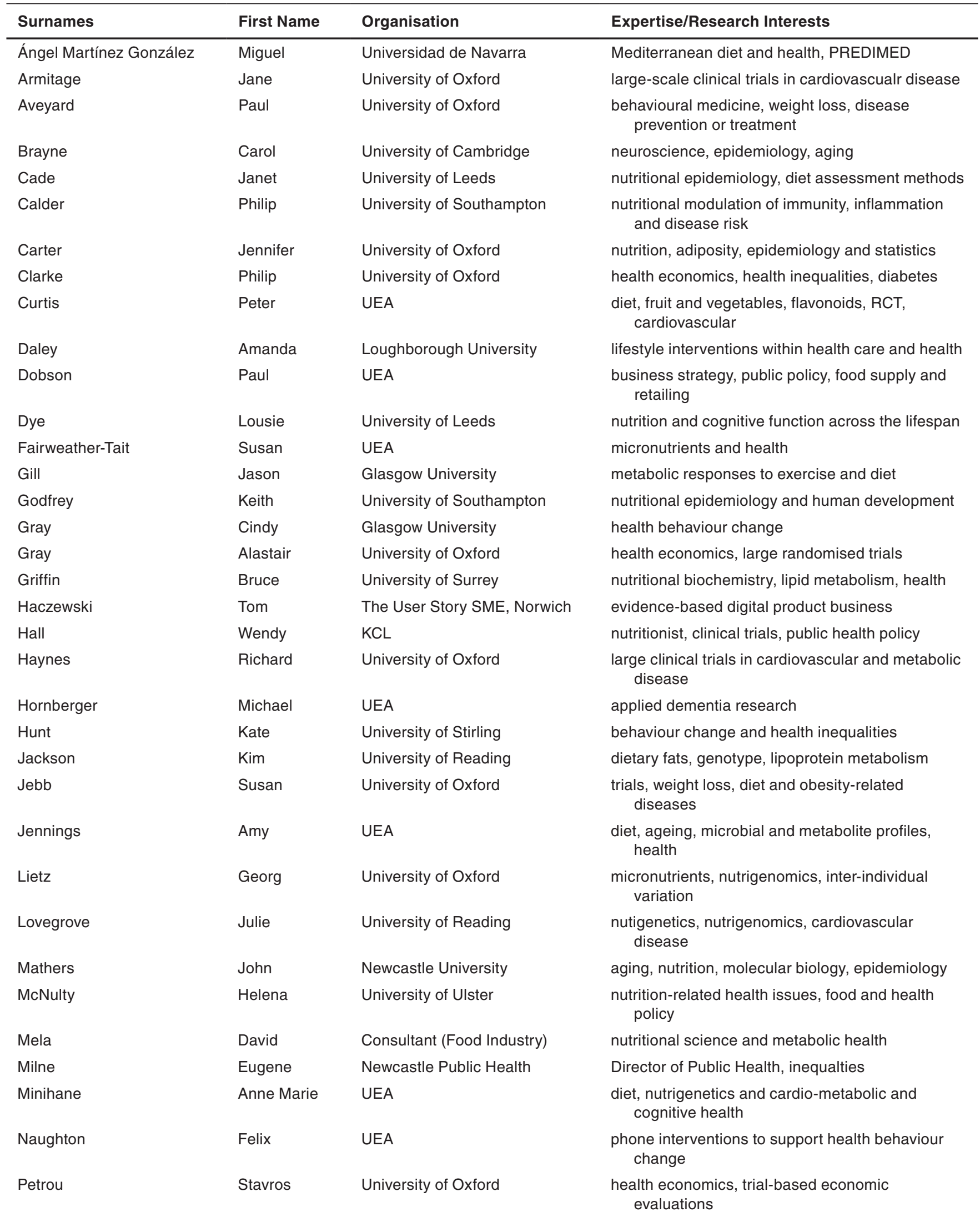




\begin{tabular}{|c|c|c|c|}
\hline Surnames & First Name & Organisation & Expertise/Research Interests \\
\hline Rogers & Peter & University of Bristol & $\begin{array}{l}\text { nutrition, behaviour, obesity and psychological } \\
\text { health }\end{array}$ \\
\hline Sattar & Naveed & Glasgow University & $\begin{array}{l}\text { epidemiology of diabetes, obesity and heart } \\
\text { disease }\end{array}$ \\
\hline Smith & Louise & Norfolk Public Health & Director of Public Health, health and wellbeing \\
\hline Sniehotta & Falko & Newcastle University & trials, behavioural change, health \\
\hline Whitty & Jenny & UEA & applied health economist \\
\hline Wildman & John & Newcastle University & health economics, health inequalities \\
\hline
\end{tabular}

\section{APPENDIX B}

\section{SYSTEMATIC SEARCH OF THE EMPIRICAL EVIDENCE ON EATING BEHAVIOUR CHANGE INTERVENTIONS}

What is the evidence for the impact of various interventions on attainment and maintenance of eating behaviour change?

Randomised controlled trials using behaviour change to improve diet (focused on whole diet).

\section{PUBMED SEARCH [1]}

randomized controlled trial AND diet AND disease AND ((double blind OR single blind)) AND adult NOT supplement

Filter 2015-2021

$[n=391]$

Excluded studies reporting single dietary components or supplements, multi domain interventions, without clearly defined behaviour change elements or lacking diet only treatment arms.

Results reported in main text.

\section{PUBMED SEARCH [2]}

Randomized controlled trial AND diet AND disease AND ((double blind OR single blind)) AND adult NOT supplement AND ((United Kingdom) OR UK).

Filter 2010-2021

$[n=94]$

Excluded studies reporting single dietary components or supplements, multi domain interventions, without clearly defined behaviour change elements, lacking diet only treatment arms or not conducted in the UK.

Results reported in Table B1.

\section{ADDITIONAL STUDIES [3]}

Large nutritional studies not covered above.

1. PREDIMED

2. Food4Me

3. NuAGE

4. CRESSIDA

5. MedEx 


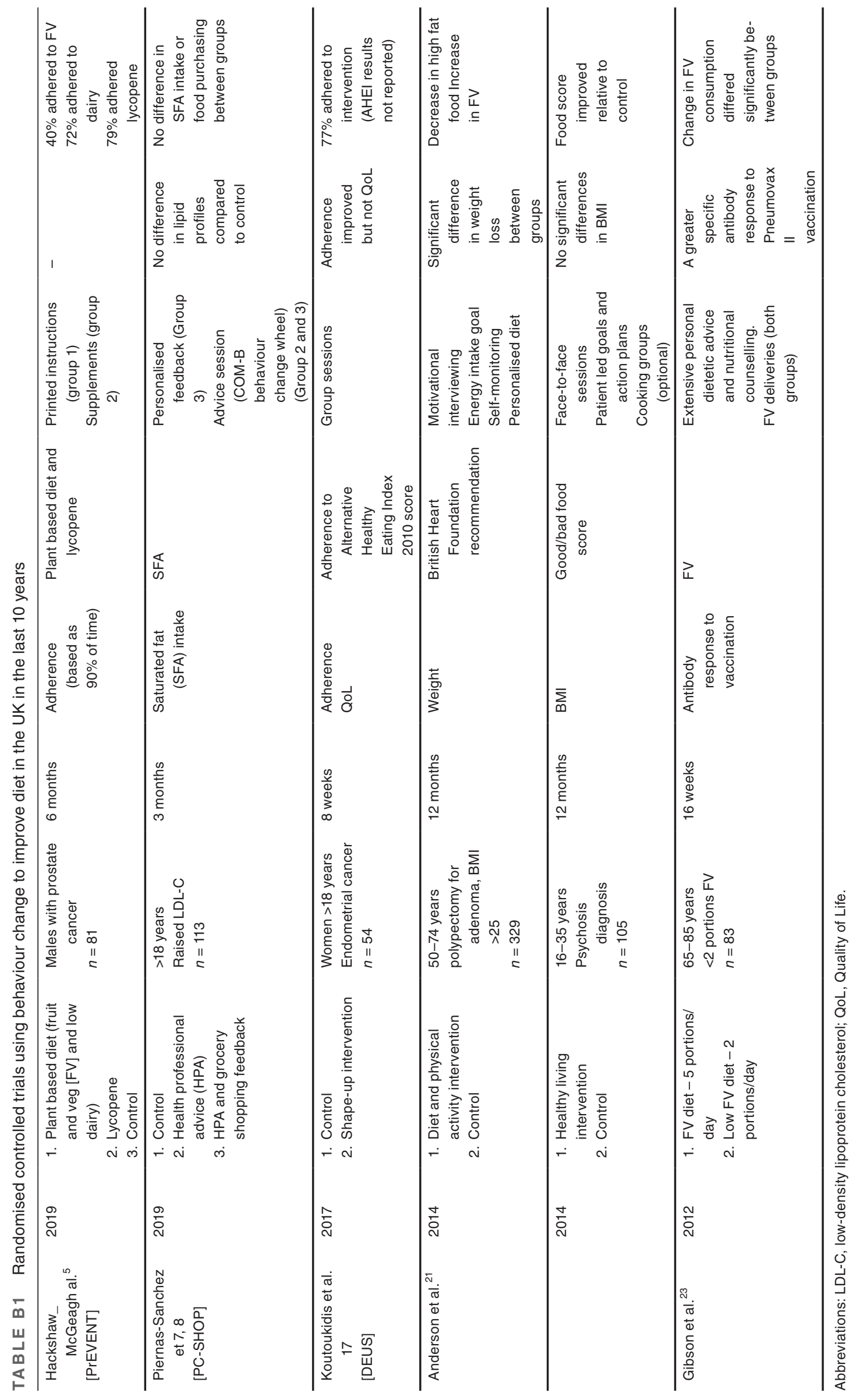




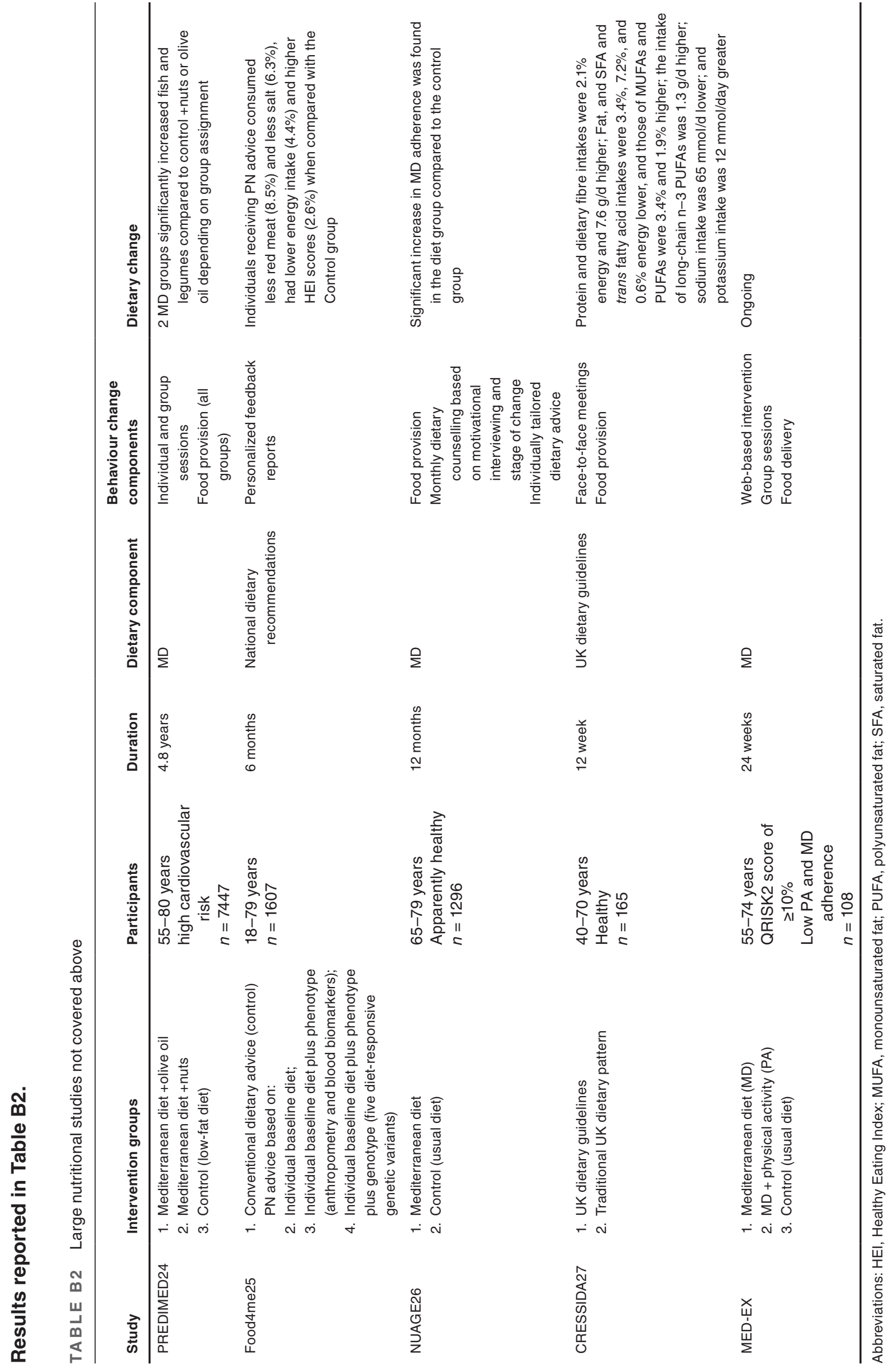

